\title{
Studies of "natural" remedies for the common cold: pitfalls and pratfalls
}

\author{
Ronald B. Turner
}

$\infty \quad$ See related article page 1043

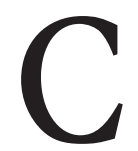

urrent treatments for the common cold are limited to symptomatic therapies. First-generation antihistamines and adrenergic agents are modestly effective for rhinorrhea and nasal obstruction respectively, but their usefulness is diminished by side effects. In recent years, there has been increasing interest in "natural" remedies for the common cold. Although there have been many clinical trials of these alternative agents, structured reviews have consistently found a high proportion of the trials to be of poor quality. ${ }^{1,2}$ The problems reported with these trials involve issues unique to the study of natural remedies as well as methodologic issues associated with common cold studies in general.

In contrast to conventional drug treatments, natural remedies are generally brought to clinical trials after anecdotal reports of benefit rather than a systematic evaluation of their pharmacologic properties. The proposed mechanism of action for a therapy for the common cold has important implications for the proper design of the trial, since the end points of the trial are different for an agent with proposed antiviral activity than for an agent that targets symptoms. The absence of information about active constituents and the mechanism of action of most natural remedies prevents the development of specific hypotheses to guide the design of clinical trials and increases the risk that statistically significant effects may be found by chance.

A second major problem identified in studies of natural remedies, especially herbal therapies, is lot-to-lot variability in the products. Assays of major constituents have been used in an attempt to standardize some products; however, this effort is hampered by the fact that in many cases the "active" constituent or constituents responsible for any beneficial effect are unknown. The use of nonstandardized products prevents comparison among different studies and generalization of study results to the use of the product in practice.

Appropriate blinding of studies of natural remedies is also an important consideration. The distinctive taste or smell of some herbal and alternative therapies poses a significant challenge to the appropriate blinding of study treatments. There are few objective measures of symptom severity of upper respiratory tract infections, and most studies rely on the subjective assessment of symptoms. The use of a subjective end point requires that the studies be carefully blinded and that the blinding be assessed. Ideally, the adequacy of the blinding should be assessed to eliminate bias caused by the subject's perception of the presence or absence of a treatment effect. This can be ensured by conducting a formal assess-

ment of blinding before the clinical trial begins or early in its course, before the subject has an opportunity to experience the outcome of interest.

In a study published in this issue ${ }^{3}$ (see page 1043), Predy and colleagues report a modest but significant effect of North American ginseng on the occurrence of viral respiratory illness. The authors have addressed some of the problems associated with studies of natural remedies. The material used was standardized to reduce lot-to-lot variability, although the phytochemical composition of the material is not provided. Also, since the true "active" constituent is not known, it is possible that there is lot-to-lot variability for important phytochemical components that are not measured. Blinding was assessed at the end of the study and was reported to be adequate. The proposed mechanism of action of ginseng is unclear. The authors provide a summary of the immunologic ef-

\section{It is not clear how the immunologic effects of ginseng relate to viral respiratory infection.}

fects of North American ginseng, but it is not clear how these relate to viral respiratory infection. Enhancement of interferon-gamma activity might be expected to reduce the severity of symptoms, but enhancement of the elaboration of inflammatory cytokines might be expected to increase the severity.4,5

Other aspects of the study design raise questions about the interpretation and generalizability of the results. The study was conducted during the influenza season and included only subjects who were not immunized against influenza. On the other hand, the case definition (Jackson colds) was based on a scoring system for symptoms of the common cold. The case definition was also substantially different from that used in previous studies of therapies for either natural colds or influenza. ${ }^{6-9}$ This study included as "colds" only illnesses with a total symptom score of at least I4 over a 2-day period. The Jackson symptom scoring method referred to by the authors ${ }^{10}$ was initially used in a rhinovirus challenge model. It defined a cold as an illness with a symptom score of at least I4 over a 6day period and included additional criteria to permit the de- 
tection of subjects who had milder illness but believed they had experienced a cold. The effect of the case definition used by Predy and colleagues is to limit the evaluation to only the most severe illnesses that occur during the influenza season.

Experience has demonstrated the difficulty and importance of sound methodology in preventing bias in studies of common cold prevention. Although numerous therapies, both alternative and conventional, have been reported in preliminary studies to have beneficial effects for the common cold, only a relative handful have proven effective after rigorous and reproducible studies. Further studies that evaluate the effect of wellcharacterized and standardized preparations of ginseng in virologically proven influenza infections or more typical common cold illnesses will be needed to confirm and extend the results of the study reported in this issue.

Ronald Turner is from the Department of Pediatrics, University of Virginia School of Medicine, Charlottesville, Virginia.

Competing interests: Ronald Turner is a consultant to Wyeth Consumer Healthcare, Schering-Plough Research Institute, Nordic Phytopharma A/S, the Dial Corporation and Procter \& Gamble. He has received research funding from Biopolymer Engineering, the Dial Corporation, Antiviral Technologies, Procter \& Gamble and ViroPharma.

\section{REFERENCES}

I. Marshall I. Zinc for the common cold. Cochrane Database Syst Rev 2000: CDoor364.

2. Melchart D, Linde K, Fischer $\mathrm{P}$, et al. Echinacea for preventing and treating the common cold. Cochrane Database Syst Rev 2000;2:CDoo0530.

3. Predy GN, Goel V, Lovlin R, et al. Efficacy of an extract of North American ginseng containing polyfuranosyl-pyranosyl-saccharides for preventing upper respiratory tract infections: a randomized controlled trial. CMAJ 2005;173(9):1043-8.

4. Gern JE, Vrtis R, Grindle KA, et al. Relationship of upper and lower airway cytokines to outcome of experimental rhinovirus infection. Am J Respir Crit Care Med 2000;162:2226-3I.

5. Fritz RS, Hayden FG, Calfee DP, et al. Nasal cytokine and chemokine responses in experimental influenza A virus infection: results of a placebo-controlled trial of intravenous zanamivir treatment. J Infect Dis I999;180:586-93.

6. Hayden FG, Albrecht JK, Kaiser DL, et al. Prevention of natural colds by contact prophylaxis with intranasal alpha2-interferon. N Engl J Med I986;314:7I-5.

7. Hayden FG, Atmar RL, Schilling M, et al. Use of the selective oral neuraminidase inhibitor oseltamivir to prevent influenza. N Engl J Med I999;34I:I336-43.

8. Monto AS, Robinson DP, Herlocher ML, et al. Zanamivir in the prevention of influenza among healthy adults: a randomized controlled trial. JAMA I999;282:31-5.

9. Monto AS, Shope TC, Schwartz SA, et al. Intranasal interferon-a2b for seasonal prophylaxis of respiratory infection. J Infect Dis 1986;154:128-33.

Io. Jackson GG, Dowling HF, Spiesman IG, et al. Transmission of the common cold to volunteers under controlled conditions. I. The common cold as a clinical entity. Arch Intern Med 1958;101:267-78.

Correspondence to: Dr. Ronald B. Turner, University of Virginia School of Medicine, P.O. Box 800386 , Charlottesville, VA 22908; fax 434 982-4246; rbt2n@virginia.edu

\section{The Declaration of Helsinki: an update on paragraph 30}

\section{Jeff Blackmer, Henry Haddad}

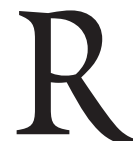

esearch on human subjects is governed by a large number and wide variety of codes and policies worldwide. In Canada, the Tri-Council Policy Statemen $\mathrm{t}^{1}$ must be adhered to by individuals and institutions who receive public funding for research. However, Health Canada and many private funding sources generally use the World Health Organization's guidelines, ${ }^{2}$ which differ slightly from the Tri-Council statement. Internationally, there is little argument that the pre-eminent document addressing research ethics is the Declaration of Helsinki, ${ }^{3}$ adopted by the World Medical Association (WMA) in 1964. This document evolved from the Nuremberg Code, which was put in place to protect human research subjects in response to atrocities committed by Nazi physicians in the name of medical science. The Declaration of Helsinki has $\therefore$ been amended 5 times, most recently in 2000 . The addition of paragraphs 29 and 30 in the amendment of 2000 has been among the more significant and controversial changes made to the document, and subsequently prompted the addition of 2 notes of clarification. The first of these, added in 2002, pertains to paragraph 29, which deals with the use of placebos. Many feel that this note has not served to clarify conditions in which placebos can ethically be used but, rather, may have weakened the intent of the existing paragraph. ${ }^{4}$ Our concern here, however, is with paragraph 30 , which addresses the issue of post-study access to treatment. This paragraph reads as follows:

At the conclusion of the study, every patient entered into the study should be assured of access to the best proven prophylactic, diagnostic and therapeutic methods identified by the study.

This addition to the Declaration has given rise to significant debate and discussion, including in the pages of the journal. ${ }^{5}$ The primary intention of the paragraph is to prevent trial sponsors from performing studies in populations that would not normally have access to the study treatment, only to remove access to the intervention once the trial has been completed. This occurred after some of the trials of HIV/AIDS drug therapy conducted in some African nations in the I99os. Some argued that the research could be justified by the devastation caused by the epidemic, and the fact that these patients could not otherwise obtain medication; others have argued that ethical standards are universal and that all research subjects deserve a certain standard of protection regardless of 